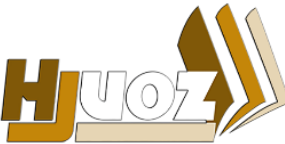

hjuoz.uoz.edu.krd

p-ISSN: 2410-7557

e-ISSN: 2518-5128
كَّوارا زانستيّن مروّقايهتى يا زانكوّيا زاخوّ

مجلة العلوم الانسانية لجامعة زاخو

Humanities Journal of University of Zakho (HJUOZ)

Vol. 5, No. 3, pp. 713-724, Sept.-2017

\title{
أثر أستخدام استراتيجية ( فكر ـ زاوج ـ شارك ) في تحصيل تلميذات الصف الرابع الأساسي في مادة الرياضيات وتنمية التفكير الاستدلالي لديهن
}

\section{لانه سعيد حميد}

قسم علم النفس، فاكولتي العلوم الانسانية، جامعة زاخو، اقليم كردستان - العراق.

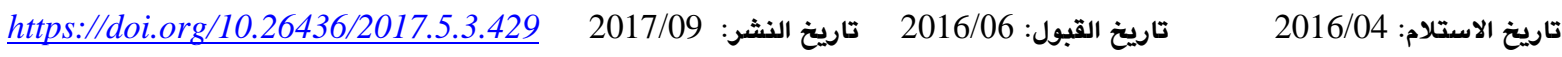

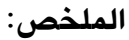

يهدف مذا البحث إلى معرفة اثر استخدام إستراتيجية ( فكر - زاوج -ثارك ) في تحصيل تلميذات الصف الرابع الأساسي في مادة الرياضيات وتنمية التفكير الاستدلالي لديهن .ولتحقيق هدفي البحث وضعت الباحثة فرضيتين صفريتين ، وقد اقتصر البحث على تلميذات الصف الرابع الأساسي للعام الدراسي( 2013 - 2014 )في مدرسة ( سه رهلدان ) التي اختيرت بصورة قصديه واعتمدت الباحثة التصميم التجريبي ذي المجموعتين : التجريبية ، والضابطة ويالاختبارين القبلي والبعدي لمتغير التفكير الاستدلالي. والاختبار البعدي فقط بالنسبة لمتغير التحصيل تكونت عينة البحث من (44) تلميذة بواقع (23)تلميذة في المجموعة التجريبية و(21 ) تلميذة في المجموعة الضابطة ، وقد اعدت الباحثة اختباراً تحصيلياً تكونت من (15) فقرة من نوع الاختيارمن متعدد وتم عرضه على مجموعة من المحكمين والخبرآ في مجال التربية وعلم النفس وطرائق التدريس لغرض تحقيق الصدق تأكد من صدقه وثباته واستخرج معاملات

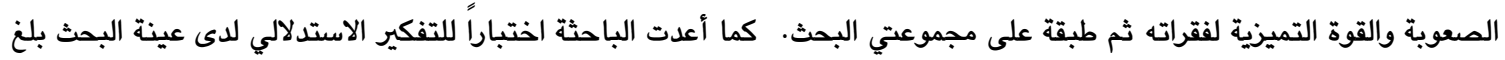
عدد فقراته (20) فقرة ، وقد أتسم بالصدق والثبات والتمييز ،كما أعدت الباحثة (36) خطة تدريسية بواقع (18) خطة حسب استراتيجية (18) ومثلها بالطريقة الاعتيادية ، وقد بدأت التجربة بتاريخ 2014/1/21، وانتهت في 2014/3/10. ويعد الانتهاء من التجربة، وتطبيق الأداتين، وإجراء التعامل الإحصائي مع البيانات باستخدام الاختبار التائي (t - test) أظهرت النتائج ما يأتي: أ. وجود فرق ذو دلالة إحصائية عند مستوى ( 0.05) بين متوسط درجات المجموعتين التجريبية والضابطة ولمصلحة المجموعة التجريبية .

ب. وجود فرق ذو دلالة إحصائية عند مستوى (0.05) بين متوسطي فرق النمو في التفكير الاستدلالي لدى المجموعتين التجريبية والضابطة ولمصلحة المجموعة التجريبية .

وفي ضوء ذلك قدمت الباحثة مجموعة من التوصيات منها : 1. إعداد برامج تدريبية لمعلمي الرياضيات في جميع مراحل التعليم لتدريجهم على كيفية استخدام إستراتيجية (فكر - زاوج - شارك) في التدريس. 2. الحث على الاهتمام بتعليم التفكير بصورة عامة والتفكير الاستدلالي بصورة خاصة. واستكمالاً لهذه الدراسة اقترحت الباحثة إجراء بحوث مستقبلية . الكلمات الدالة: استخدام إستراتيجية (فكر، زاوج، شارك)، مادة الرياضيات، التنمية، التفكير الاستدلالي.

من خلال أستشارتها لعدد من المدرسين والمدرسات والمختصين في مادة الرياضيات أن هنالك صعويات تواجه المتعلمين في فهم هذه المادة وترجع إلى أسباب عديدة أهمها : طرائق وأساليب عرض مادة الرياضيات في غرفة الصف غير مجدية ينبغي تغيرها حيث أن معظم المعلمين يفتقرون إلى استخدام الأساليب الحديثة في تدريس الرياضيات ويستخدمون الطرائق التقليدية حيث يهتمون بنقل المعلومات الى

\section{1.مشكلة البحث}

تعد الرياضيات إحدى المواد الدراسية التي تواجه المتعلمين صعوية في فهمها وأستيعابها إذا تم استخدام الطرق التقليدية في تدريسها والتي تحرمهم من المشاركة الفاعلة في عملية التعلم لذلك تصبح الحاجة ملحة لإستخدام طرائق وأستراتيجيات ونماذج تدريسية حديثة تزيد من فاعلية التدريس وترفع من المستوى التحصيلي للمتعلمين ، فقد وجدت الباحثة 
لدى المتعلم في تحمل مسؤولية تعلمه والمشاركة فعلياً مما ينعكس ايجابياً على مستوى تحصيله العلمي وزيادة شعوره بالرضا عن الخبرات

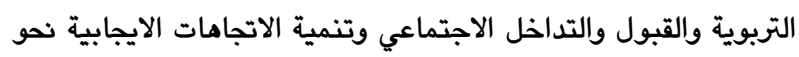
أفراد المجموعة والمجموعات الأخرى وتعزيز عمليات التفكير العليا وتنميتها والتي يمكن أن تؤدي الى التفكير الفوقي ( زيتون ، 2007 :

وذهب ( Cook , 1990 ) الى ماذهب اليه غيره من أن طريقة التعلم

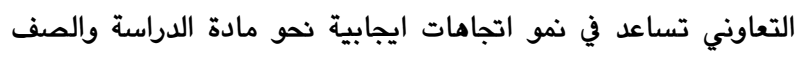
وشعور الطلبة بالنجاح عند تطبيقها ، كما أنها تعزز الناحيتين التحصيلية والاجتماعية (47-46 : Cook , 1990 ) ويعتمد نجاح أعضاء مجموعات التعلم التعاوني على نجاح كل عضو فيها ويجري ذلك عندما يشعر كل عضو في المجموعة ويجري ذالك عندما يشعر كل عضو في المجموعة ان عليه العمل بجد لانجاح العمل المطلوب ويدرك انه مرتبط مع الاخرين بطريقة لايستيع فيها ان ينجع الا اذا نجحوا جميعا وفشله هو فشل المجموعة وعليه فكل فرد سيبذل قصارى جهده ليساعد الآخرين على النجاح ويشاركهم فيما لديه من معارف ويمنحم التأييد والمؤازرة ويستمتع ويسعد بنجاحهم ويدرك كل عضو من أعضاء المجموعة بأن أداءه والحصول على النتائج للمجموعة

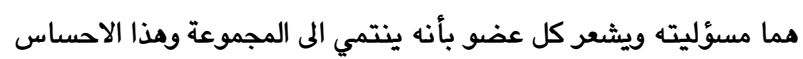

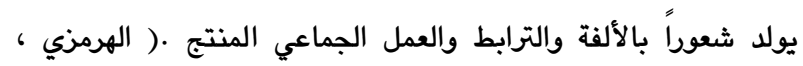
(5-3 : 1995

وتعد استراتيجية ( فكر - زاوج - شارك ) من استراتيجيات مجموعة النقاش التي تندرج من المنحى البنيوي ، وهي طريقة من الطرائق

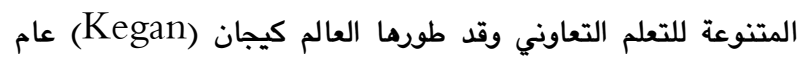
1990 ويتم فيها تزويد المعلمين بطرائق مرنة لتطبيق التعلم التعاوني

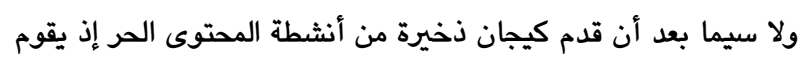
المدرس باختيار المحتوى المناسب وعليه يتم إعداد درس كامل

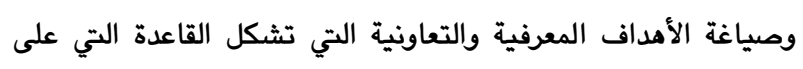
أساسها يتم اختيار تتابعات الأنشطة وترتيبها وتندرج تحت هذه تهنيه الطريقة استراتيجية ( فكر - زاوج - شارك ) ( سعادة وآخرون ، 2008

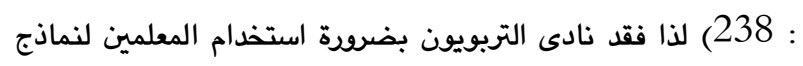
وطرائق واستراتيجيات تدريس بنائية تتيح للمتعلم الدور الفاعل في عملية التعليم والتعلم ، بحيث لا يكون متلقياً سلبياً فقط لكنها تنمي مهارات

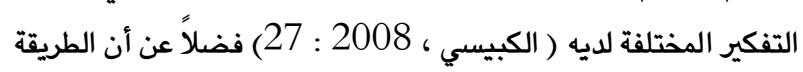
التي تقوم على المشاركة والتعاون تعد المحرك الفعال للعملية التربوية نحو تحقيق أهدافها فهي تساعد على تنمية التفكير لدى المتعلمين (

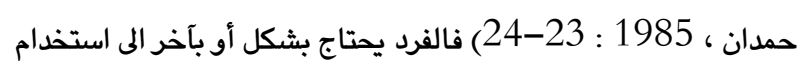
نوع من أنواع التفكير لحل الكثير من المشكلات التي تواجهه في حياته وقد حث القرآن الكريم على التفكير بأنواعه المختلفة والتأمل والتدبر وهناك الكثير من الآيات القرآنية الدالة على ذلك ومنها قوله تعالى ( قل على بلى
المتعلمين ولكنهم لا يهتمون بتدريبهم على العمليات العقلية المتضمنة في عملية التفكير ، ، لذا أختارت الباحثة أحد نماذج التعلم التعاوني وهو أنموذج ( فكر - زاوج - شارك ) ولعل استخدامه في تدريس الرياضيات قد يؤدي الى زيادة التحصيل الدراسي لدى المتعلمين ونماء تفكيرهن الاستدلالي ، ومما سبق تبرز مشكلة البحث بالسؤال الآتي: ما أثر أستخدام أنموذج ( فكر - زاوج - شارك ) في تحصيل تلميذات الصف الرابع الأساسي في مادة الرياضيات وتنمية التفكير الاستدلالي لديهن ؟ الد 1.1 يتميز العصر الذي نعيشه حيث لا حدود للعلم فيه ولا مدى بالتغير السريع والتقدم والتطور العلمي والتكنولوجي والانفجار المعرفي في

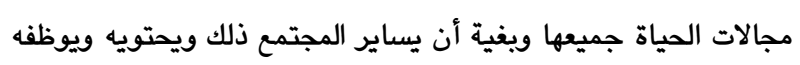
أحسن توظيف لابد أن يعد ويأهل أفراده إعداداً وتأهيلاً يحققون هذا الغرض لا بل يكونون قادرون على مجابهة الصراعات والتعقيدات اللتين تفرزان نتيجة لذلك وأن يرتقون في التكيف الى المستوى الذي يتحقق فئون

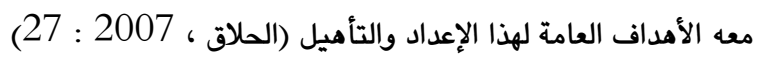

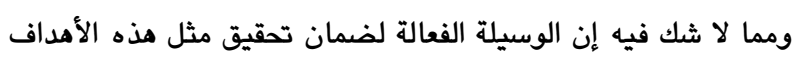
أو الغايات هي التربية ويذلك أصبحت التربية ولاسيما في البلدان المتقدمة اداة للتغيير بعد أن كانت أداة للجمود فأصبحت وسيلة لصنع الإنسان الجديد من خلال تنمية تفكيره وخبراته ومهاراته من خلال أفكارها الضخمة (الزويعي ، 1981 : 12 ) فهي تهدف إلى مساعدة الفرد على تلى النمو في النواحي الجسمية والعقلية والأنفعالية والاجتماعية ليصبح قادراً على التكيف مع نفسه ومع الآخرين (أبو جادو، 2003 : 25) وأحد

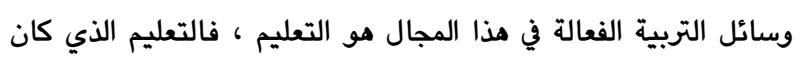
بسيطاً وسطحياً في السابق أصبح متطوراً الآن وذلك من خلال استخدام الطرائق والأساليب التدريسية الحديثة التي يجعل المتعلم محوراً للعملية التعليمية والتي يمكن عن طريقها تحسين عمليتي التعليم والتعلم .

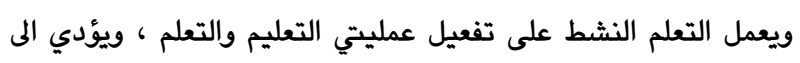
تنشيط المتعلم وجعله يشارك بفعالية وتتمثل الغاية من نهج التعلم النشط في مساعدة المتعلمين على اكتساب مجموعة من المهارات والمعارف والاتجاهات والمبادئ والقيم إضافة الى تطوير استراتيجيات التعلم الحديثة التي تمكنهم من الاستقلال في التعلم وقدرتهم على حل مشكلاتهم الحياتية واتخاذ القرارات وتحمل مسؤوليتها والتعلم النشط هي طريقة التدريس التي تدمج مجموعة منوعة من الأنثطة لجعل الدماغ يعمل فالطلاب بحاجة الى أن يسمعوا أو يروا ويسألوا ويتناقشوا وييحثوا

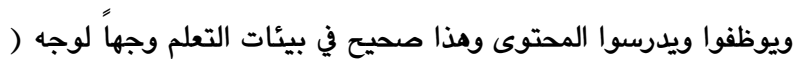

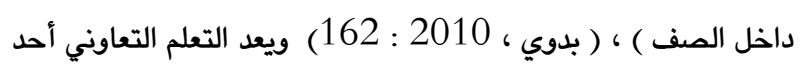

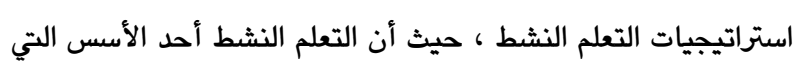

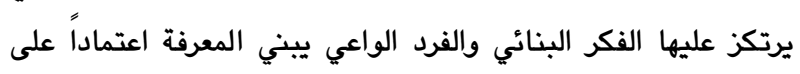

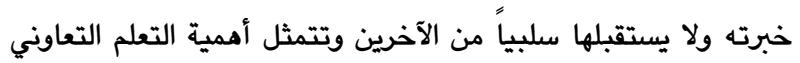


4. لما كان هدف الرياضيات تنمية التفكير لدى المتعلمين لذا فإن مذه الدراسة تكتسب أهميتها من خلال بناء اختبار للتفكير الاستدلالي وييان أثر إستراتيجية (فكر - زاوج - ثارك ) فيه وفي التحصيل . 5. يعد محاولة لمعرفة مستوى التفكي الاستدلالي لدى تلميذات الصف

$$
\text { الرابع الاساسي }
$$

6. الخروج بنتائج وتو صيات قد تساهم في بحوث مستقبلية لباحثين آخرين وإغناء المكتبة بمعرفة علمية حول متغيرات البحث.

2.1

$$
\text { يهدف البحث التعرف إلى }
$$

1- أثر استخدام استراتيجية (فكر ــ زاوج ـ ـ شارك ) في تدصيل تلميذات الصف الرابع الأساسي في مادة الرياضيات 2- أثر استخدام استراتيجية (فكر - زاوج - شارك ) عند تدريس مادة الرياضـيات لتلميذات الصـف الرابع الأسـاسـي في تنمية تفكيرهن

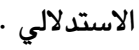

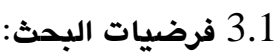
1- لا يوجد فرق ذو دلالة إحصـــائية عند مســـتوى (0.05) بين متوسط تدصيل تلميذات المجموعة التجريبية اللاتي يدرسن على وفق أستراتيجية (فكر ـ- زاوج _ شارك ) ومتوسط تدصيل تلميذات المجموعة الضابطة اللاتي يدرسن على وفق الطريقة الاعتيادية في مادة الرياضيات. 2- لا يوجد فرق ذو دلالة إحصـــائية عند مســتوى ( 0.05 ) بين متوسـط تنمية التفكير الاســدلالي لدى تلميذات المجموعة التجريبية

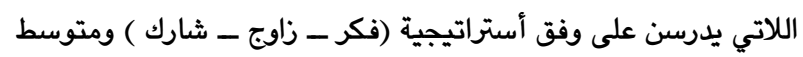
درجات تنمية التفكير الاســتلالي لدى تلميذات المجموعة الضـــابطة اللاتي يدرسن على وفق الطريقة الاعتيادية في مادة الرياضيات. 4.1

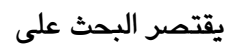
1-تلميذات الصف الرابع الأساسي في المدارس الأساسية الصباحية في مركز محافظة دهوك للعام الدراسي 2013 - 2014. 2- الفصل (السابع _ الثامن _التاسع) من كتاب الرياضيات للصف مهردي الرابع الأساسي باللغة الكوردية (سولاقا، 2008 : 117-181). 3- الفصل الدراسي الثاني للسنة الدراسية 2013-2014. 5.1 1.5.1. أستراتيجية (فكر - زاوج - شارك) عرفه كل من :

Jensen, Sharon 1996 .1 بأنها نشاط تعليمي جماعي ذو ثلاث خطوات محددة ومشروطة حيث تتضمن شروطا محددة لتطبيقها هي التفكير الفردي والمزاوجة والمشاركة الجماعية (Jensen, Sharon 1996:56)
مل يستوي الأعمى والبصير أفلا تتفكرون ) ( الأنعام ، الآية 50 ) وكذلك أهتم الكثير من علماء النفس بالتفكير بوصفه من العمليات

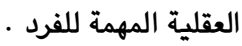
فالتفكير عبارة عن سلسلة من النشاطات العقلية التي يقوم بها الدماغ عندما يتعرض لمثير يتم أستقباله عن طريق واحد أو أكثر من الحواس الخمس والتفكير بمعناه الواسع عملية بحث عن المعنى في الموقف أو الخبرة ( جروان ، 1999 : 33) فالتفكير ضرودي لنمو القدرات العقلية العليا لدى الطلبة إذ يساعد على إمعان النظر في الأشياء للوصول الى الحكم السديد وله صور متعددة تختلف باختلاف الغرض الذي يرمي اليه المفكر والتفكير أياً كانت صورته هو إدراك العلاقات ( محمد ، . 2004

ولقد أصبح تعليم التفكير من الأهداف العامة والأساسية للتخطيط التربوي في المجتمعات المعاصرة فالمجتمعات لاتتطور ولا تتقدم إلا بتطور عقول أفرادها ويقدراتهم على استخدام أساليب التفكير المختلفة ومنها التفكير الاستدلالي ل فالتفكير الاستدلالي من أهم أنواع التفكير التي تساعد المتعلمين للوصول الى معلومات أخرى متاحة والتعرف على المعلومات الصحيحة والمفيدة من التدفق الهائل للمعلومات بحيث يستطيع المتعلم توظيف هذه المعلومات لتحقيق أهدافه وأهداف مجتمعه . إذ يعد هذا النوع من

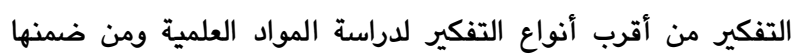
الرياضيات لأنه يساعد الى التوصل الى مكونات بيئة العلم من حقائق ومفاهيم وتعميمات وقوانين ونظريات كما يعد أحد العمليات العقلية الهامة التي تعين الفرد على فهم ومعالجة المشكلات التي يقابلها في المواقف التعليمية والحياتية المختلفة مما يجعله يعد من أهم الأمداف لهمي الأساسية لتعليم الرياضيات ، ويؤكد ذلك خليفة (2006) حيث يرى أن تنمية التفكير الاستدلالي يعد هدفاً من أهداف تدريس العلوم

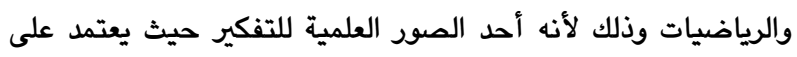
الأساليب المنطقية في بحث وتفسير الظواهر المختلفة والمشكلات التي قد يواجهها المتعلمون أثناء دراستهم أو في حياتهم المستقبلية. ( خليفة ( 211 : 2006 ، وفي ضوء ما تقدم يمكن إجمال أهمية البحث في النقاط الآتية: 1. يتماشى البحث الحالي مع الاتجامات التربوية الحديثة التي تسعى لتجريب استراتيجيات حديثة في التدريس من بينها أستراتيجية (فكر زاوج - شارك ) لخلق روح التعاون بين الطلبة . 2. إثراء بيئة التعلم من خلال استخدام استراتيجيات تدريس فعالة يكون فيها المتعلم محور العملية التعليمية بدلاً من الأساليب التقليدية التي تجعل المتعلم مستقبلا سلبيا 3. المساعدة في تطوير طرائق تدريس الرياضيات، إذ أن تجريب هذه

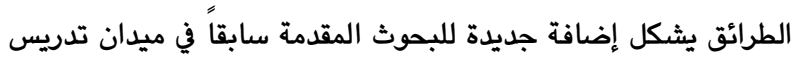
الرياضيات بشكل عام 
الخاص (اسـتنباط ) أو من الخاص إلى العام (أسـتقراء ) أو أسـتنتاج نتيجة من حقائق معينة (اســتنتاج) ويتم قياسـه بمقدار الدرجة التي

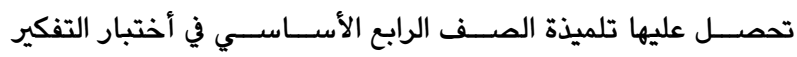
الاستدلالي الذي أعدته الباحثة .

\section{2 الخلفية النظرية}

1.2 استراتيجية (فكر، زاوج، شارك): تعتبر استراتيجية ( فكر _ زاوج _ شارك ) احد استراتيجيات التعلم التعاوني النشط حيث تستخدم لتنشيط مالدى التلاميذ من معرفة سابقة للموقف التعليمي أو لإحداث رد فعل حول مشكلة رياضية ما ، فبعد أن يتم بشكل فردي التأمل والتفكير لبعض الوقت يقوم كل زوج من التلاميذ بمناقشة أفكارهما لحل المشكلة معا ثم يشاركا زوج آخر من التلاميذ في مناقشتهما حول نفس الفكرة وتسجيل ما توصلوا اليه

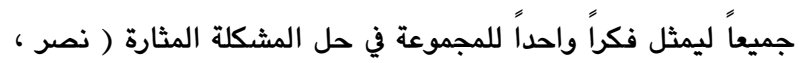
( $213: 2003$

تعتمد استراتيجية ( فكر _ زاوج _ شارك ) على ثلاث خطوات أو مراحل وهي : 1.1 .2 الخطوة الأولى (فكر Think) : يطرح المعلم سؤالاً أو مسألة ترتبط بالدرس ويطلب من المتعلمين أن يقضوا دقيقة يفكر كل منهم في المسألة والكلام والتجوال غير مسموح لهما في وقت التفكير.

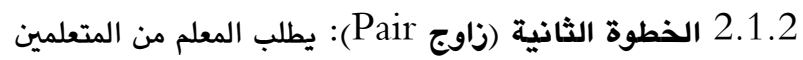
أن ينقسموا المى أنواج ويناقشوا ما فكروا فيه ويمكن أن يكون التفاعل خلال هذه المدة الاشتراك في الاجابة إذا كان السؤال قد طرح أو الاشتراك في الأفكار إذا كان قد ثم تحديد مسألة معينة ومدة هذه الخطوة 4-5 الخدان دقائق (جابر ، 1999: 91: 3.1 .2 الخطوة الثالثة (شارك Share): وفيها يعبر المتعلمون لفظياً عن إجاباتهم عن السوال أمام الصف عن طريق المناداة عليهم من قبل المدرس للمشاركة في أفكارهم ومن خلال رفع الأيدي تؤخذ الاجابات ويمكن أن ينظموا إجاباتهم على شكل جدول أو خرائط أو رسوم بيانية للتأكد من صحتها وفي ضوء توجيهات المعلم يتم تبادل الخبرات بين جميع المتعلمين والتي ينتج عنها أكثر من حل أو إجابة صحيحة للسؤال أو المشكلة المطروحة وقد تجري مناقشة تفاعلية عن كيفية الوصول الى الحل أو الاجابة وهذا بدوره قد يتطلب تفكيرًا وتحليلاً

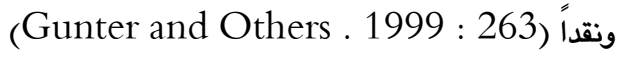
ومما سبق من تعريف لخطوات استراتيجية ( فكر - زاوج - شارك ) ترى الباحثة إن هذه الاستراتيجية توفر فرصاً للتفكير الفردي وعلى عرض من كل فرد ما فكر يه مع زميل له وعلى المشاركة التعاونية وعلى التعليم

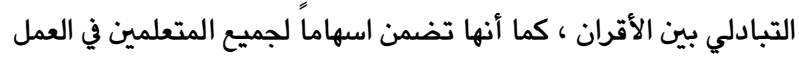
والى جانب ذلك فإن للمعلم دود أساسي يتمثل في الاعداد والتخطيط للعمل بهذه الاستراتيجية وذلك قبل تنفيذها داخل الصف ومن حيث
2. جابر(1999) : " انها احد استراتيجيات التعلم التعاوني التي تتضمن خطوة التفكير التي يطلب فيها المدرس من الطلاب أن يفكر كل منهم بمفرده وان التجول والكلام غير مسموح بهما بعد طرح المدرس سؤالا يرتبط بالدرس وفي خطوة المزاوجة يطلب المدرس من الطلاب أن يناقشوا ما فكروا فيه في شكل أنواج في خطوة المشاركة يطلب المدرس من كل نوج أن يشا رك مع الصف كله فيما تم التحدث

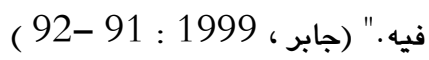
3. نصر (2003): بأنها إحدى استراتيجيات التعلم التعاوني فبعد أن يفكر كل تلميذ بمفرده في معلومة ما، يفكر مع زميله ليكونا زوجاً قد بد إندات يجلس بجواره أو مقابلا له، ثم تأتى المشاركة حيث يفكر كل زوج مع نوج آخر ليكونوا معاً المريع الطلابي" عندئذ يمارس كل تلميذ دورا

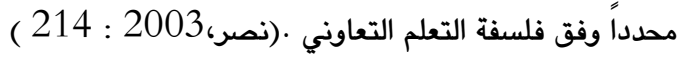
4. عبيد (2004): "بأنها عبارة عن استراتيجية تدريسية مشتقة من التعلم التعاوني وتجمع بين مميزات كل من (التفكير الفردي) دون مقاطعة احد في حالة أعطاء وقت للتفكير في خطوة التفكير وأسلوب (تدريس الأقران) في خطوة المزاوجة والتعلم التعاوني في (خطوة المشاركة) ." (عبيد، 2004 : 120 ) 2.5.1 1. عرفه صليبا (1971) عملية عقلية منطقية ينتقل فيها الفكر إلى قضية مجهولة من قضية معلومة ، وقد يكون الأستدلال استنباطيًا ينتقل فيه الفكر من العام إلى الخاص ، وقد يكون استقرائيًا ، ينتقل فيه الفكر من الخاص إلى العام ، وقد يكون استدلالاً رياضيًا يبدأ فيه من الواقع لا من حيث مادته وإنما من حيث مقاديره ومقاييسه ( صليبا ، 1971) 2. وعرفه (Rips 1990). بأنه القدرة على التعليل المنطقي، والاستنتاج، وإدراك العلاقات للربط بين الأسباب والنتائج، وهو يتضمن بذلك عمليات مثل التجريد والتوصل إلى التعميمات،واثبات علاقات، والتوصل إلى حلى لهول للمشكلات، وتقييم الآراء واستنباط النتائج (Rips 1990). 3. عرفه جروان (1999) بأنه عملية عقلية يتم بموجبها التوصل إلى قرار أو استنتاج وتوليد معرفة جديدة من معلومات متوفرة باستخدام قواعد وأستراتيجيات

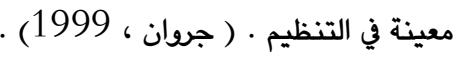

$$
\begin{aligned}
& \text { 4.عرفه عبد الرحيم (2009) }
\end{aligned}
$$

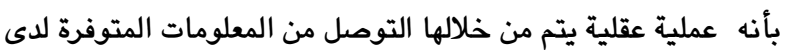
الطالب إلى معلومات آخرى تحمل أكثر من معنى · ( عبد الرحيم ، ( 42 : 2009

$$
\text { التعريف الإجرائي للتفكير الاستدلالي }
$$

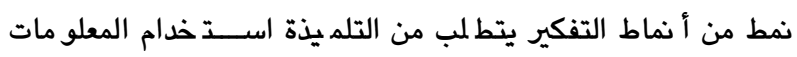
المختلفة والخروج بعلاقات منظمة فيما بينها سـواء كانت من العام إلى مي لم 
3. يوزع المتعلمين الى مجموعات النقاش ويعمل على أن يكون هناك تباين في كل مجموعة وكذلك يتحكم بالمدة الزمنية لكل مرحلة من مراحل استراتيجية ( فكر - زاوج - شارك ) 4.2 دور المتعلم في استراتيجية (فكر، زاوج، شارك): يقدم المتعلمون مجموعة متنوعة من الخبرات والإمكانات والاهتمامات في أي موضوع جديد وتساعد الدراسة الدقيقة لخلفيات المتعلمين العملية والاستفادة من الخبرات المتشابهة والمتعلم في هذه الاستراتيجية له دود نشط يمتاز بالنشاط والتفاعل والحيوية داخل الصف ولايتوقف دوره على تلقي المعلومات انما دوره إيجابي ويبادر في التعلم ويشارك ويناقش ويتفاعل مع زملائه الآخرين ·

5.2 الدراسات السابقة أجرى عدد من المتخصصين، والباحثين التربويين، المهتمين بطرائق

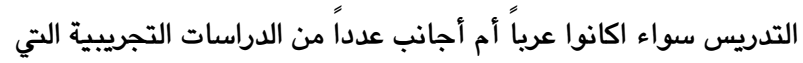
تناولت اثر استراتيجية (فكر - زاوج -ثارك ) ي مختلف العلوم

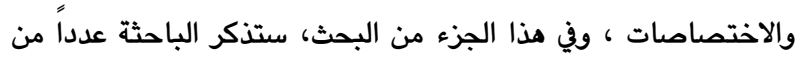

مذه الدراسات ويحسب تسلسلها الزمني، ومنها: 1.5.2 دراســة خاجي (2010): أجريت مذه الدراســــة في العراق ومنهات يهدف مذا البحث إلى التعرف على فاعلية استراتيجية ( فكر - زاوج شارك ) في اكتساب المفاهيم الفيزيائية وتنمية الاتجاه نحو حل مسائل الفيزياء لدى تلميذات الصف الأول المتوسط ، تكونت عينة البحث من (52) تلميذة وقد اســخدم الباحث المنهج التجريبي وتحددت الادوات في اختبار تحصـــيلي لقياس اكتســــاب المفاهيم الفيزيائية ومقياس الاتجاه نحوحل مسائل الفيزياء واستخدم الباحث اختبار (T-Test) وأظهرت النتـائج وجود فرق ذو دلالـة احصـــــائيـة بين المجموعتين ولصالح المجموعة التجريبية. ( خاجي ، 2010 )

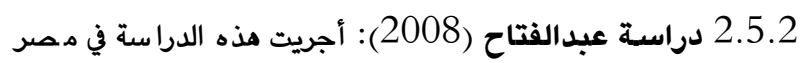

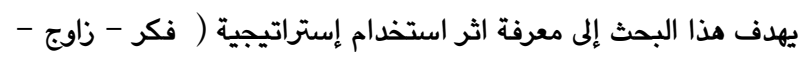
شـارك ) على تنمية التواصـل والإبداع الرياضـي لدى تلاميذ المرحلة

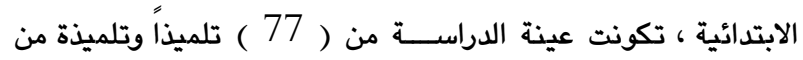
تلاميذ الصف الخامس الابتدائي ، تحدت الادوات في اختبار التواصل الرياضي واختبار الابداع الرياضي وكلاهما من اعداد الباحثة وأستعمل

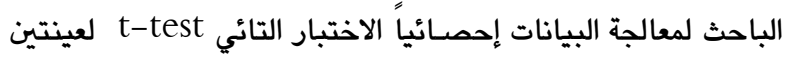
مستقلتين وتو صلت الدرا سة الى فعالية استخدام ا ستراتيجية ( فكر -

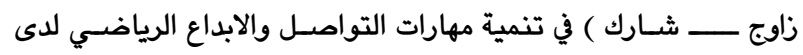
التلاميذ حيث وجد ان هناك حجم اثر كبير لاستراتيجية ( فكر - زاوج -

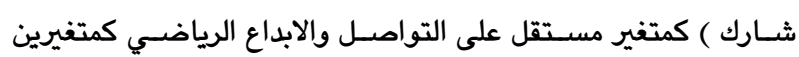

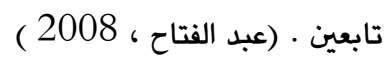
3.5 .2 دراسة نصر (2003): هدفت هذه الدراسة لبيان أثر

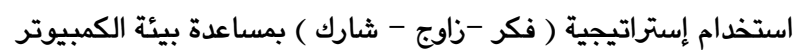

تصوره لطريقة تقسيم المجموعة واعداد الأنشطة التي سيكلف الطلاب بها وفي أثناء الدرس يتابع عمل المجموعات ويرد على الاستفسارات ويستمع الى المناقشات داخل المجموعات ويلاحظ آداء المتعلمين ويقدم

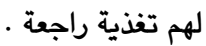

2.2 مميزات استراتيجية (فكر، زاوج، شارك) في تعليم وتعلم الرياضيات أكدت الأدبيات والدراسات التربوية أن استراتيجية ( فكر - زاوج - شارك ) تتصف بعدد من المميزات يمكن ايجازها فيما يلي :

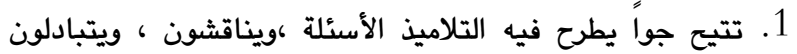
الأفكار ، وتقديم وتلقي المساعدة واستكثاف المواقف ، والبحث عن الأنماط والعلاقات في مجموعة من البيانات وصياغة الافتراضات واختيارما بحرية . 2. تعمل على تعزيز الأتصال الشخصي والتفاهم بلغة الرياضيات من بن خلال مناقشة التلاميذ بعضهم لبعض . 3. تتيح للتلاميذ فرصة تعلم طرق وأساليب مختلفة لحل نفس المشكلة والقدرة على التوصل الى العلاقات الرياضية . 4. تكسب الحيوية لحجرة الدراسة ويتم ذلك من خلال العمل الزوجي وكذلك تهيء مناخاً صحياً مفعماً بالنشاط والفعالية يساعد على دراسة الدية

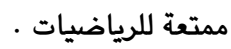
5. تكون مذه الاستراتيجية تلاميذ يعملون ويفكرون فيما يدرسونه ويتحدثون عنه وهذه المناقشة تأصل وترسخ محتوى رياضي متماسك وثابت في أذهانهم بشكل أفضل كما تنمي قدراتهم على الاستدلال المنطقي 6. تتيح للتلاميذ فرصة كتابة أفكارهم وحلولهم في كروت ويتم جمعها وفحصها من جانب المعلم مما يعطيه فرصة كي يرى الى أي مدى استطاع التلاميذ استيعاب المعلومات والبيانات في المشكلات المطروحة وإن كانت لديهم صعوية في الفهم أم لا.( هندي ، 2002 : 183) ، ( نصر ، 2003 : 216 ( 2003

3.2 دور المعلم في استراتيجية (فكر، زاوج، شارك): دور المعلم في استراتيجية ( فكر , زاوج , شارك ) إيجابي ونشط وليس سلبي حيث له عدة مهام يقوم بها منها : 1. طرح سؤال أو مشكلة ذات نهاية مفتوحة وذلك لاستثارة تفكير المتعلم في مشكلة أو ظاهرة معينة وكذلك منح المتعلم الوقت الوقت المحدد للتفكير في الإجابة مع مراعاة تفكير المتعلم لوحده دون الاستعانة بأحد . 2. منح المتعلمين فرصاً للمشاركة في الإجابات مع مجموعة صغيرة أو الصف بأكمله . الصف 


\section{1 إجراءات البحث}

\section{3}

اعتمدت الباحثة على التصـــميم التجريبي ذو الضــــبط الجزئي لأنه يناســب البحث الحالي ويحقق أهدافه حيث يتضــــمن هذا التصــميم مجموعتين متكافئتين في عدد من المتغيرات ( فان دالين ، 2007 :

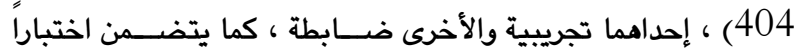
قبلياً ويعدياً للمتغير التابع (التفكير الاســـدلالي) واختباراً بعدياً فقط للمتغير التابع (التحصيل) والمخطط أدناه يوضح ذلك:

\begin{tabular}{|c|c|c|c|}
\hline \multicolumn{4}{|c|}{ التصميم التجريبي للبحث } \\
\hline المتغير التابع & المستقل & الاختبار & المجموعة \\
\hline - الدراسي & (فكر، زاوج، & \multirow{2}{*}{ الاستيلير } & التجريبية \\
\hline الاستدلالي & الاعتيادية & & الضابطة \\
\hline
\end{tabular}

2.3 مجتمع البحث وعينته:

1. مجتمع البحث : يتكون مجتمع البحث من تلميذات الصف الرابع الأساسي في مدارس مركز محافظة دموك النهارية للعام الدراسي . (2014-2013)

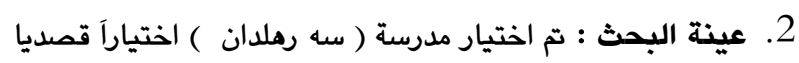
لتطبيق تجربة البحث بلغ عدد تلميذات الصف الرابع الأساسي في هذه المدرسة (115) تلميذة ، موزعين على أربعة شعب ، اختارت الباحثة شعبتين من هذه الشعب ، تكونت عينة البحث( بعد استبعاد التلميذات

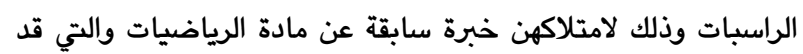

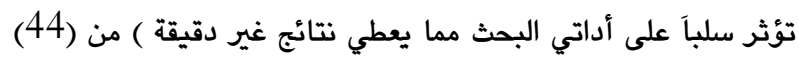
تلميذة بواقع (23)تلميذة في المجموعة التجريبية و(21 ) تلميذة في المجموعة الضابطة فمثلت عشوائيا الشعبة (ب) المجموعة التجريبية واختيرت شعبة (ج) لتمثل المجموعة الضابطة

\section{3 تكافؤ مجموعتي البحث:}

حرصــت الباحثة قبيل البدء بالتجربة أن تجري التكافؤ بين تلميذات مجموعتي البحث إحصـائياً في عدد من المتغيرات التي تعتقد أنها تؤثر في نتائج التجربة ودقتها ، ومذه المتغيرات هي حاصـــلـ الذكاءحيث طبقت الباحثة اتبار الذكاء المصـور الذي أعده ( أحمد زكي صـالح ) وقننه القزاز للبيئة العراقية (القزاز ، 1989 : 116) واختبار المعرفة

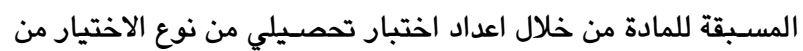
متعدد و الاختبار القبلي للتفكير الاستدلالي والجدول (1) يوضح ذلك:
والمواد البيئية التناولية في تدريس هندسة الصف الرابع الابتدائي على التحصيل والاحتفاظ والاعتماد الإيجابي المتبادل ، تكونت عينة البحث

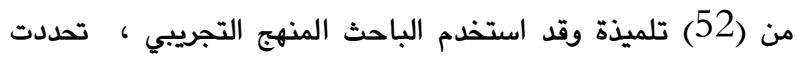
الادوات في اختبار التحصيل والاحتفاظ ومقياس الاعتماد الايجابي من وندي المدئ اعداد الباحث ومن أهم النتائج التي توصلت اليها الدراسة وجود فرق ذو دلالة احصائية بين المجموعتين في التحصيل والاحتفاظ والاعتماد

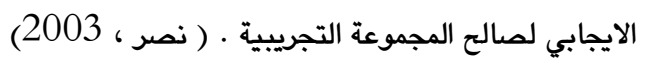
6.2 موازنة بين الدراسات السابقة: 1. اتفقت الدراسـات السـابقة من حيث الهدف حيث هدفت الى معرفة أثر اسـتخدام اسـتراتيجية ( فكر _ زاوج _ شـارك ) في التحصـيل مع

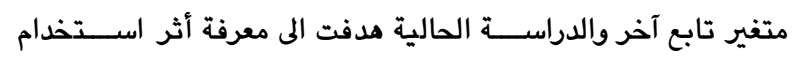
إسـتراتيجية ( فكر -زاوج - شــارك ) في التحصـيل وتنمية التفكير · الاستدلالي

2. تباينت احجام العينلت المســـــدمة في الدراســات الســابقة تبعاً للمناهج المعتمدة في تلك الدراسات والمتغيرات التي تناولتها كل دراسة حيث بلغت حجم عينة دراستي ( 52 - 77) تلميذ وتلميذة واقتصرت درا ستي ( خاجي 2010 ) و ( ذصر 2003 ) على الاناث ودرا سة ( ) عبد الفتاح 2008 ) اقت صرت على الذكور والاناث ، والدرا سة الحالية اعتمدت على الإناث فقط وقد بلغت عدد أفراد عينتها (44) تلميذة . 3. تم تطبيق اسـتراتيجية ( فكر -زاوج - شـارك ) في مراحل ومواد دراسـية مختلفة ولم يقتصـر تجريته على مرحلة دراسـية معينة فقد

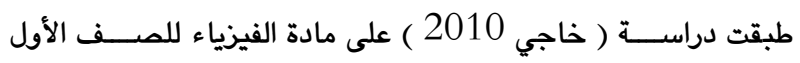
المتوسـط ، ودراسـة ( عبد الفتاح 2008 ) طبقت على الرياضـيات للصف الخامس الابتدائي أما دراسة ( نصر 2003 ) فقد تم تطبيقها بم ساعدة بيئة الكمبيوتر على هند سة الصف الرابع الابتدائي و سوف تعتمد الدراسة الحالية الصف الرابع الأساسي مجالا للتطبيق .

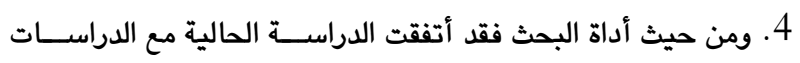
السابقة في قيام الباحثين في اعداد أدوات بحوثهم .

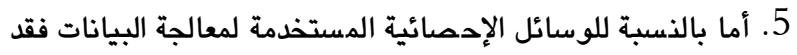
أتفقت الدراســة الحالية مع الدراســات السـابقة في اســتخدام الاختبار التائي لمعالجة وتفسير البيانات . 6. أظهرت نتائج الدراســات الســـابقة والدراســـة الحالية على فاعلية اســتخدام اســتراتيجية ( فكر - زاوج - شـــارك ) في تدريس المواد العلمية وسوف تستعين الباحثة بنتائج الدراسات السابقة في مناقشتها

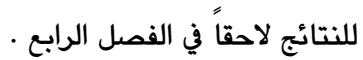
7. وأخيراً أفادت الباحثة من الدراسات السابقة في جوانب عديدة منها لإسا بلورة مشكلة البحث ، وتحديد المصطلحات ، والاطار النظري ، واعداد الخطط التدريســية لكل مجموعة واختيار العينة ومتغيرات تكافئها واختيار الوسائل الإحصائية الملائمة لمعالجة بيانات الدراسة . 
الجـدول (1): نتائج الاختبار التائي لدلالة الفرق بين متوسط درجات تلميذات مجموعتي البحث في اختبار حاصل الذكاء والمعرفة المسبقة والاختبار القبلي

\begin{tabular}{|c|c|c|c|c|c|c|c|}
\hline \multicolumn{8}{|c|}{ للتقكير الاستدلالي } \\
\hline \multirow{2}{*}{ مستوى الدلالة عند } & \multicolumn{2}{|r|}{ القيمة التائية } & \multirow{2}{*}{ الانحراف } & \multirow{2}{*}{ المسابي } & \multirow[b]{2}{*}{ 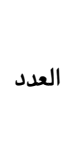 } & \multirow[b]{2}{*}{ المجموعة } & \multirow[b]{2}{*}{ المتغيرات } \\
\hline & الجدولية & المحسوية & & & & & \\
\hline \multirow{6}{*}{ غير دالة } & \multirow{6}{*}{2.021} & \multirow{2}{*}{0.749} & 6.673 & 30.260 & 23 & التجريبية & \multirow{2}{*}{ حاصل الذكاء } \\
\hline & & & 6.201 & 28.809 & 21 & الضابطة & \\
\hline & & \multirow[b]{2}{*}{0.718} & 1.879 & 9.478 & 23 & التجريبية & \multirow[b]{2}{*}{ المعرفة المسبقة } \\
\hline & & & 2.132 & 9.074 & 21 & الضابطة & \\
\hline & & \multirow{2}{*}{0.195} & 3.363 & 10,04 & 23 & التجريبية & \multirow{2}{*}{ اللتفكيرالاستدلالي } \\
\hline & & & 2.850 & 9.857 & 21 & الضابطة & \\
\hline
\end{tabular}

والمادة التعليمية للمجموعتين التجريبية والضابطة ويواقع (18) خطة تدريسية بحسب استراتيجية ( فكر - زاوج - شارك ) ومثلها بحسب الطريقة المتبعة وقد تم عرضها على مجموعة من المحكمين ذوي

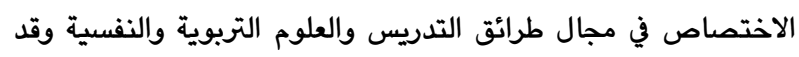
قامت الباحثة بتعديل الخطط بناءاً على الملاحظات المقدمة من السادة المحكمين لتخرج بصورتها النهائية.

5.3

1.5.3 الاختبار ألتحصيلي:وتمثلت في اعداد ويناء اختبار تحصيلي ، يستخدم في قياس مدى تحصيل التلميذات للمادة التعليمية ، أعدت

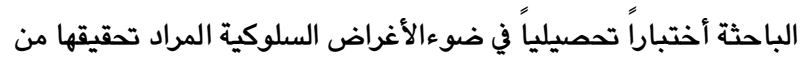
قبل أفراد عينة البحث على وفق مستويات بلوم للمجال المعرفي (

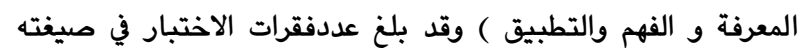

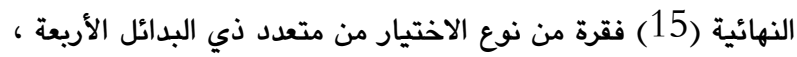
وقد عرضت فقرات الاختبار على مجموعة من المحكمين من ذوي الخبرة

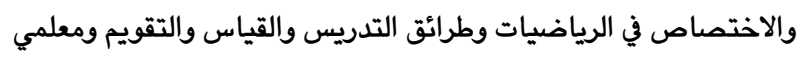
ومعلمات المادة حول صلاحية الأداة وقد حصلت على نسبة إتفاق أكثر من 85٪ ويذلك تدقق صدق الاختبار ، وأوجدت الباحثة صعوية فقرات

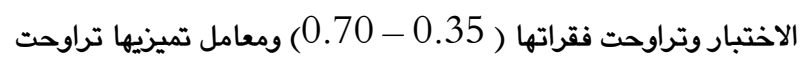
بين ( 0.33 - 0.62) ثم تم حساب ثبات الاختبار بطريقة التجزئة النصفية باستخدام معامل ارتباط بيرسون ويلغ (76\%) ثم صحح معامل

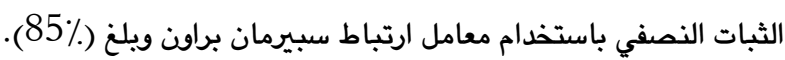

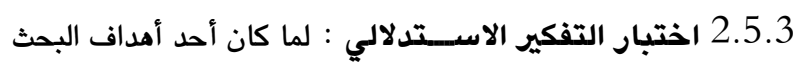
الحالي التعرف على أثر استخدام استراتيجية ( فكر - زاوج - شارك ) في تنمية التفكير الاسـتدلالي، لذا أصــبح من الضـروري إعداد اختبار

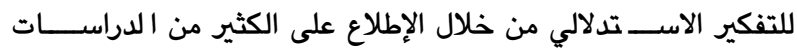
والأدبيات ذات العلاقة وقد بلغ عدد فقرات الاختبار في صـيغته النهائية
يتضـح من الجدول (1) إن القيمة التائية المحسـوية لجميع المتغيرات أ قل من القيمة الجدولية وهذا يدل على عدم وجود فرق ذو دلالة احصـائية بين متوسـطي المجموعتين في متغيرات التكافؤ ، ويهذا تعد المجموعتان متكافئتين . 4.3 1.4 .3 تحديد المادة العلمية: تم تحديد المادة الدراســية المقرد تدريسها لعينة البحث بالفصلين السابع والثامن من كتاب الريا ضيات المقرر للصف الرابع الأساسي للعام الدراسي (2014-2013)

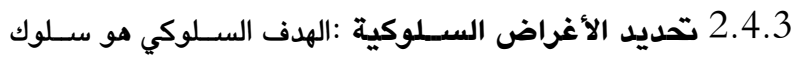
مرغوب فيه يتحقق لدى المتعلم نتيجة نشــــاط يزاوله كل من المعلم والمتعلمين ومو سلوك قابل لأن يكون موضع ملاحظة وقياس وتقويم (الكبيسي ، 2008 : 35 ) وفي ضـوء تحديد المادة التعليمية المقرر تدريسـها خلال فترة التجربة قامت الباحثة بصـياغة عدد من الأغراض الســلوكية موزعة على المســـويات الثلاثة الدنيا من تصـــيف بلوم

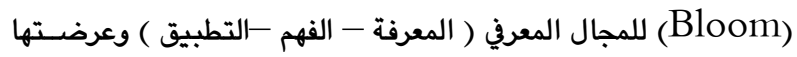
البـاحثـة مع المـادة المقررة على مجموعـة من المحكمين من ذوي الاختصاص في مجال التربية وعلم النفس وطرائق التدريس وذلك لبيان رأيهم في سلامة صياغتها وصحة تصنيفها ووضوحها ومدى تغطيتها

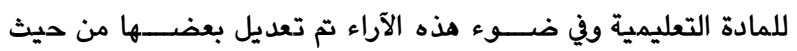
الصياغة والسلامة اللغوية . 3.4.3 إعداد الخطط التدريسية : يقصد بالخطط التدريسية تصورات مسبقة للمواقف والإجراءات التدريسية التي يضطلع بها المدرس وطلبته لتحقيق أهداف تعليمية معينة وتضم هذه العملية تحديد الأهداف واختيار الطرائق التي تساعد على تحقيقها ، ولما كان إعداد الخطط التدريسية واحدا من متطلبات التدريس الناجح ، فقد أعدت الباحثة خططاً تدريسية في ضوء الأهداف السلوكية المحددة 
أستخدم لأغراض تكافؤ مجموعتي البحث ومعرفة الدلالة المعنوية بينهما في التحصيل والتفكير الاستدلالي. 1. معامل ارتباط بيرسون لحساب معامل ثبات اختبار التفكير الاستدلالي. 2. معادلة سبيرمان __ براون

لتصحيح معامل ارتباط بيرسون لغرض حساب معامل ثبات اختبار التفكير الاستدلالي. (الكيلاني و نضال ، 2007 : 429)

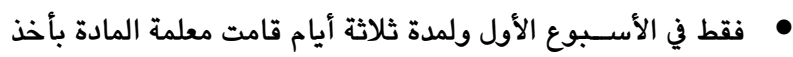
محاضرتين في اليوم الواحد وللمجموعتين

\section{4. عرض النتائج وتفسيرها}

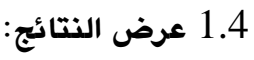

1.1.4 النتائج المتعلقة بالفرضية الصفرية الأولى: بعد تصحيح إجابات أفراد العينة على الاختبار التحصيلي تم تحليلها إحصائيا في ضوء فرضية البحث وللتحقق من صحة الفرضية الصفرية الأولىفقد تم إيجاد المتوسط الصسابي والانحراف المعياري لدرجات مجموعتي البحث من الاختبار التحصيلي فأظهرت النتائج وجود فرق بين متوسطيدرجات تحصيل المجموعتين ولاختبار دلالة هذا الفرق استخدمت الباحثة الاختبار التائي لعينتين مستقلتين فكانت النتائج كما مبين في الجدول

الجــدول (2): نتائج الاختبار التائي لدلالة الفرق بين متوسط درجات

\begin{tabular}{|c|c|c|c|c|c|c|}
\hline \multirow{2}{*}{ الإحصائية } & \multicolumn{2}{|c|}{ القيمة التائية } & \multirow{2}{*}{ الانحراف } & \multirow{2}{*}{ الحسابي } & \multirow[t]{2}{*}{ العدد العد } & \multirow[t]{2}{*}{ المجموعة } \\
\hline & الجدولية & المحسوبة & & & & \\
\hline \multirow[b]{2}{*}{ دالة } & \multirow[b]{2}{*}{2.021} & \multirow[b]{2}{*}{3.654} & 2.587 & 14.173 & 23 & التجريبية \\
\hline & & & 2.315 & 11.476 & 21 & الضابطة \\
\hline
\end{tabular}

ومن الجدول يبين أن الفرق بين المتوسطين ذو دلالة إحصائية و لصالح المجموعة التجريبية ، ويذلك ترفض الفرضية الصفرية الأولى. يتضح من الجدول (2) أن القيمة التائية المحسوية بلغت (3.654) وهي أكبر من قيمتها الجدولية البالغة (2.021) عند

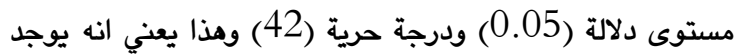
فرق ذو دلالة إحصائية بين متوسط درجات تلميذات المجموعة التجريبية ومتوسط درجات تلميذات المجموعة الضابطة ولصالح تلميذات المجموعة التجريبية، ويذلك ترفض الفرضية الصفرية الأولى، 2.1.4 النتائج المتعلقة بالفرضية الصفرية الثانية: بعد تصحيح إجابات أفراد العينة على اختبار التفكير الاستدلالي تم تحليلها إحصائياً في ضوء فرضية البحث وللتحقق من صحة هذه الفرضية ثم إيجاد المتوسط الحسابي والانحراف المعياري لدرجات مجموعتي البحث
(20) فقرة من نوع الاختيار من مت عدد ذي البدائل الأربعة ، وقد عرضــــت فقرات الاختبار على مجموعة من المحكمين من ذوي الخبرة والاختصـاص في الرياضـيات وطرائق التدريس والقياس والتقويم حول صــلاحيةالآداة وقد حصــلت على نســبة إتفاق أكثر من 87\% ويذلك تحقق صــدق الاختبار ، وقد أتســمت الفقرات بصــعوية ( 0.30 0.66) وقوة تميزية ( 0.35 - 0.68) واختارت الباحثة طري قدة إعادة الاختبار لدساب ثبات الاختبار التفكير الاستدلالي ، إذ اعتمدت

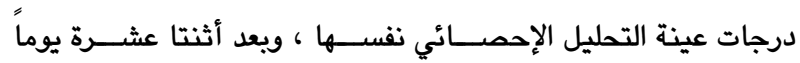
أعادت تطبيق الاختبار على العينة نفســـها ويعد تصـــيح الإجابات وحســـاب معا مل ارتباط بيرســون - Coefficient

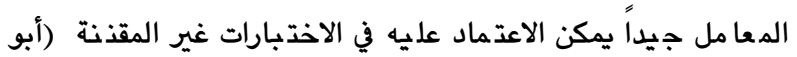
علام ، 2007 : 490) ويعد اكتمال الإجراءات الإحصـــائية المتعلقة بفقرات الاختبار أصــبح بصــورته النهائية جاهزا للتطبيق على عينة البحث تم حسـاب ثبات الاختبار بطريقة التجزئة النصـفية باســخدام

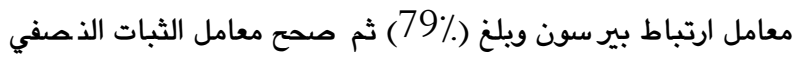

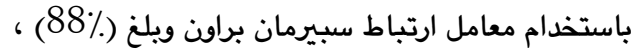
حيث يتكون الاختبار من المجالات الآتية : 1. الاستنتاج: عملية استدلال منطقي بحت، ويتضمن المحاكمة العقلية من الاحتمالية إلى الواقع التجريبي وذلك بغية التحقق من صحة الفرض، وتقترح أسباب محتملة وتوليفات للأسباب، ومن ثم التوصل إلى النتائج بطريقة منطقية (إذا كان .. فإن). 2. الاستقراء: الحكم على الكلي من خلال جزئياته ، وهو الاستقراء

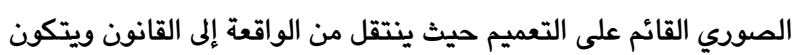
من قضيتين ينتج عنهما قضية ثالثة وتسمى القضيتان المقدمتان والقضية الثالثة تسمى النتيجة وتكون أعم من المقدمتين (مهدي ، . $27: 1999$

3. الاستنباط :وتتمثل في قدرة الفرد على استخلاص للعلاقات بين الوقائع المعطاة له بحيث يحكم على مدى ارتباط نتيجة ما مشتقة من تلك الوقائع ارتباطاً حقيقياً أم لا بغض النظر عن صحة الوقائع المعطاة أو موقف الفرد منها ـ ( عبد السلام وسليمان ، 1982 : 8 ) 3.6 تطبيق التجربة: بدأت التجربة في 21/ 2014/1 ولغاية 2014/3/10 وقد كلفت الباحثة معلمة المادة بتدريس المجموعتين وفقاً للخطط التدريسية لكل مجموعة ويواقع خمسة محاضرات في الاسبوع * بعد ذلك ثم تطبق الاختبار التحصيلي واختبار التفكير الاستدلالي ثم صحصت الاجابات ورتبت البيانات لإجراء التحليلات الإحصائية . 3.7 الوسائل الاحصائية: 3.7 .1 الاختبار التائي لعينتين مستقلتين 
ج· إن استخدام إستراتيجية (فكر، زاوج، شارك) في تدريس مادة الرياضيات له أثر فعال في زيادة التحصيل الدراسي لدى تلميذات

$$
\text { الصف الرابع الأساسي. }
$$

د. إن استخدام إستراتيجية (فكر، زاوج، شارك) في تدريس مادة الرياضيات لتلميذات الصف الرابع الأساسي له فاعلية وأثره الايجابي في تنمية التفكير الاستدلالي لديهن.

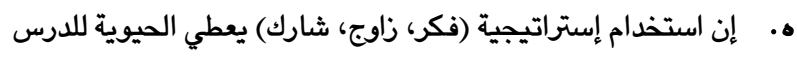
ويزيد من حماس المتعلمين وجذب انتباههم والتشويق للدرس المقبل 2.5

$$
\text { في ضوء نتائج البحث توصي الباحثة بما يأتي : }
$$

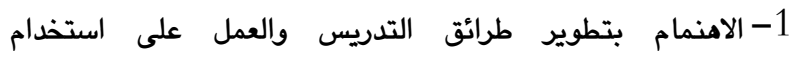
استراتيجيات حديثة توفر أكبر قدر ممكن من مشاركة المتعلمين في الموقف التعليمي مثل إستراتيجية (فكر، زاوج، شارك) 2- إعداد برامج تدريبية لمعلمي الرياضيات في جميع مراحل التعليم لتدريبهم على كيفية استخدام إستراتيجية (فكر، زاوج، شارك) في

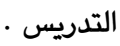
3- توجيه عناية القائمين على العملية التعليمية الى ضرورة الاهتمام بتنمية التفكير بصورة عامة والتفكير الاستدلالي بصورة خاصة . 3.5 استكمالاً للفائدة المتوخاة من البحث الحالي تقترح الباحثة إجراء الدراسات الآتية 1- أثر إستراتيجية (فكر، زاوج، شارك) في التحصيل في الرياضيات و تنمية التفكير الاستدلالي في مراحل تعليمية أخرى كالثانوية والجامعة . 2-مقارنة لأثر استخدام إستراتيجية (فكر، زاوج، شارك) مع نماذج مانج

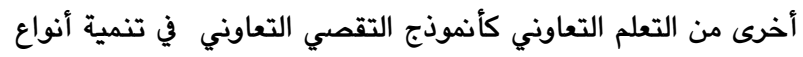
أخرى من التفكير كالتفكير (الرياضي ، الهندسي ، العلمي ، الإبداعي) لدى تلميذات الصف الرابع الأساسي في مادة الرياضيات

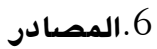

1.6 - المصادر باللغة العربية:

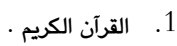
2. أبو جادو ، صالح محمد علي (2003) ، علم النفس التربوي ، ط2 ، عمان : دار المسيرة للنشر والتوزيع والطباعة .

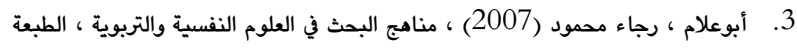

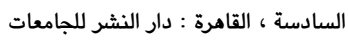

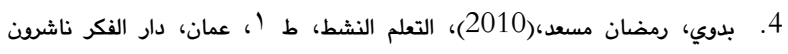
5. جابر ، عبد الحميد (1999)،" استراتيجيات التدريس والتعلم "، الطبعة الأولى ، دار

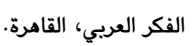
6. جروان، فتحي (1999)، تعليم التفكير: مفاهيم وتطبيقات،الطبعة الأولى، دار الكتاب الجامعي، الامارات العربية المتحدة.
لاختبار التفكير الاستدلالي فأظهرت النتائج وجود فرق بين متوسطي فرق النمو في التفكير الاستدلالي لدى تلميذات مجموعتي البحث ولاختبار دلالة مذا الفرق استخدمت الباحثة الاختبار التائي لعينتين مستقلتين فكانت النتائج كما مبين في الجدول (3)

\begin{tabular}{|c|c|c|c|c|c|c|}
\hline \multirow{2}{*}{ الإحصائية } & \multicolumn{2}{|c|}{ القيمة التائية } & \multirow{2}{*}{ الانحراف } & \multirow{2}{*}{ الحسابي } & \multirow[t]{2}{*}{ العدد العد } & \multirow[t]{2}{*}{ المجموعة } \\
\hline & الجدولية & المحسوية & & & & \\
\hline \multirow[t]{2}{*}{ دالة } & \multirow[t]{2}{*}{2.021} & \multirow[t]{2}{*}{3.5} & 2.071 & 5.34 & 23 & التجريبية \\
\hline & & & 0.850 & 3.66 & 21 & الضابطة \\
\hline
\end{tabular}
الجدول (3): نتائج الاختبار التائي لدلالة الفرق بين متوسط درجات

يتضح من الجدول (3) أن القيمة التائية المحسوية بلغت (3.5) وهي أكبر من قيمتها الجدولية البالغة (2.021) عند مستوى دلالة (0.05)

ودرجة حرية (42) ، ومذا يعني وجود فرق بين متوسط درجات تنمية التفكير الاستدلالي لدى تلميذات المجموعة التجريبية وتلميذات المجموعة الضابطة و لصالح تلميذات المجموعة التجريبية أي أن لاستراتيجية ( فكر - زاوج ـ شارك ) فاعلية أكثر في تنمية التفكير الاستدلالي ويدلالة معنوية مقارنة بالطريقة الاعتيادية ويذلك ترفض الفرضية الصفرية الثانية 3.1.4 تفسير النتائج: يتضح من الجدول (2) و(3) أن استخدام إستراتيجية ( فكر- زاوج - شارك) كان له دور كبير في تحصيل التلميذات في مادة الرياضيات و تنمية التفكير الاستدلالي لديهن وترى الباحثة إن إستخدام تلميذات المجموعة التجريبية

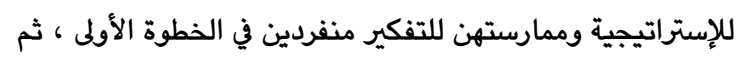
مشاركة كل تلميذة مع زميلتها في أفكارما ومعلوماتها وإدارة الحوارات الثنائية في الخطوة الثانية ، ثم المناقشات الجماعية في الخطوة الثالثة والأخيرة أثناء تدريسهن للوحدة ساعدت التلميذات على تبادل الأفكار فيما بينهن وشد النتباههن نحو الدرس وزيادة حماسهن ودافعيتهن نحو التعلم مما يزداد من تحصيلهن في المادة الدراسية كما أن التدريس باستخدام استراتيجية تعتمد على

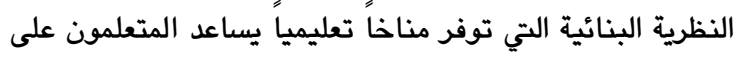
الوصول الى المعلومات والتأكد من صحتها من خلال ممارسة مهارات التفكير المختلفة من الملاحظة والاستنتاج والاستنباط تسهم في تنمية التفكير بشكل عام لديهم والتفكير الاستدلالي بشكل خاص والقدرة على التعبير عن الأفكار وشرحها وتفسيرها ، وقد جاءت هذه النتيجة متفقة مع نتيجة كل من ( خاجي 2010) و (عبدالفتاح 2008 ) و و ( نصر 2003).

$$
\text { 5.الاستنتاجات والتوصيات والمقترحات }
$$

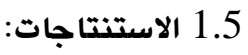

في ضوء النتائج التي توصلت إليها الباحثة يمكن استنتاج ما يأتي: 
22. محمد،جاسم محمد (2004) ،علم النفس التربوي وتطبيقاته،ط1، مكتبة دار الثقافة

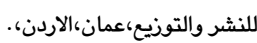

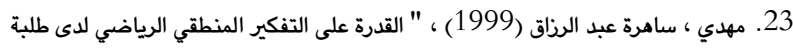

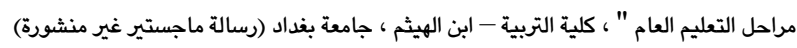

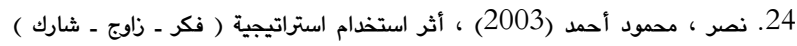

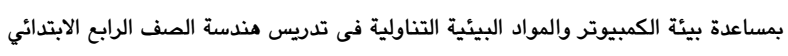

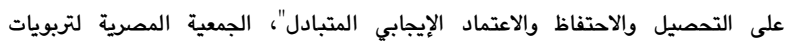

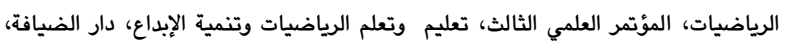

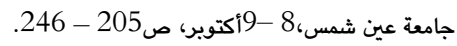
25. الهرمزي ، جانيت نيسان متي (1995): " اثر استعمال التعلم التعاوني في تغيير مفاهيم الطلبة للصف السادس الأساسي للمفهوم البيولوجي - أجهزة الجسم " الجامعة الأردنية ، كلية الدراسات العليا، (رسالة ماجستير غير منشورة) . 26. هندي ، محمد حماد (2002) : أثر تنوع بعض الثردان استراتيجيات التعلم النشط في تعليم

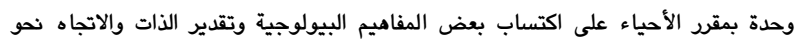

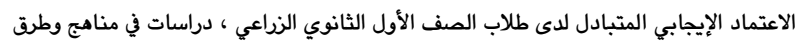
التدريس ، الجمعية المصرية للمناهج وطرق التدريس العدد (79)

2.6. المصادر باللغة الاجنبية:

27. Cook L. (1990), The Impact of Cooperative Learning Strategies on Professional and Graduated Education Students at California State University., Dissertation Abstract International, vol. 51, No. 1, P. 39.

28. Gunter, A, et al, 1999 Strategies for Reading to Learn, Think Paire, Share in Instruction : A Models Approach, 3 edition, Boston, Allyn \& Bacon , 279 .

29. Jensen, Sharon , 1996 , Enhancing Possible Sentence Through Cooperative Learning ( open to suggestion) " Journal of Adolescent and adult Lit racy, Eric Document

30. Rips. L, J (1990): Reasoning. Annual Reviews Psychology, 4,PP .321-353.

3.6. - 3.6 - المصادر الكوردية:

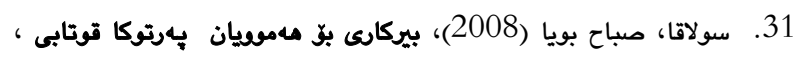

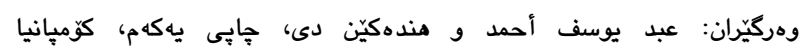

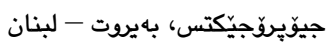

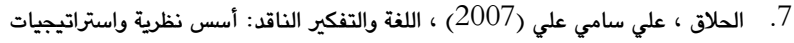
تدريسية ، الطبعة الأولى ، عمان : دار المسيرة للنشر والتوزيع والطباعة .

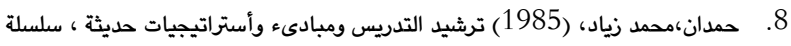
التربية الديثة عمان : دار التربية الحديثة.

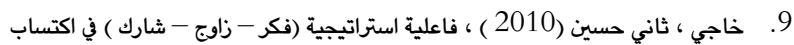

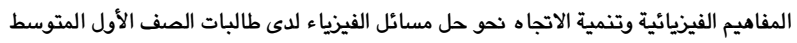

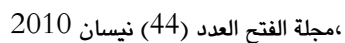
10. خليفة ، أحمد خليفة (2006 نيسان ) ، فاعلية برنامج لتنمية مهارات قراءة الرياضيات وأثره

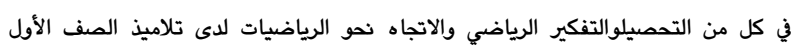

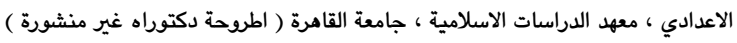

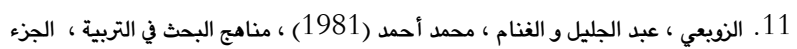

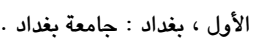

12. زيتون ، عايش محمود (2007) ، بلغاد : جامعة بغ ، النظرية البنائية واستراتيجيات تدريس العلوم ، ط1

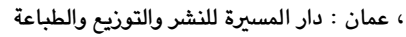
13. سعادة، جودة احمد، وآخرون (2008) ، التعلم التعاوني (نظريات وتطبيقات ودراسات)، ط ( ، عمان، دار وائل للنشر أخرن

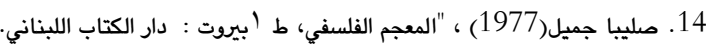

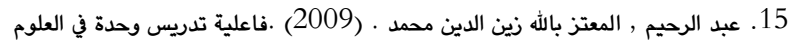

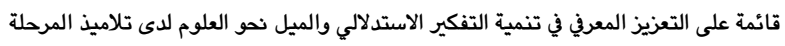

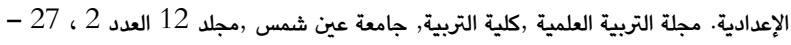

16. عبد السلام وسليمان (1982) ، كتيب اختبار التفكير الناقد ، مركز البحوث التربوية والنفسية ، كلية التربية ، جامعة أم القرى . 16 كان.

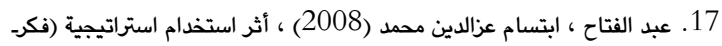

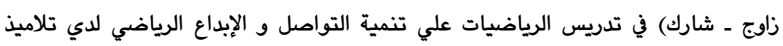

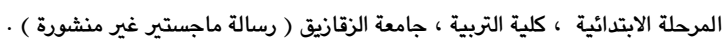

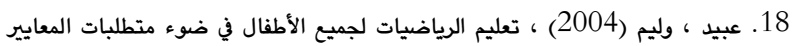
وثقافة التفكير ، عمان : دار المسيرة . 19. فان دالين ، ديو بولد .ب (2007) ، مان ، مناهج البحث في التربية وعلم النفس، ترجمة: محمد نبيل نوفل وآخرون ، القاهرة : مكتبة الأنجلو المصرية.

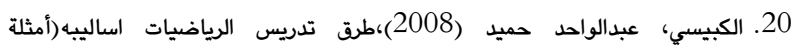

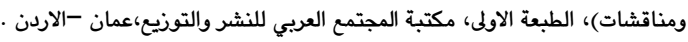

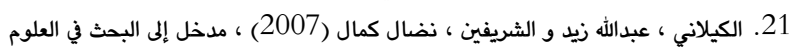

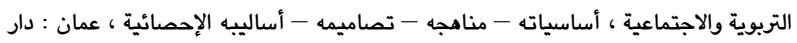

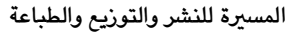




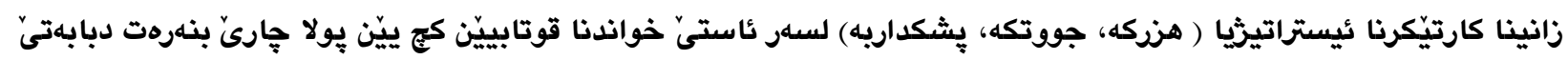

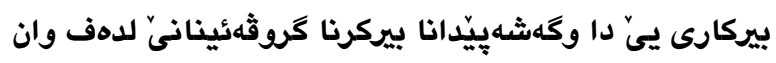

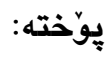

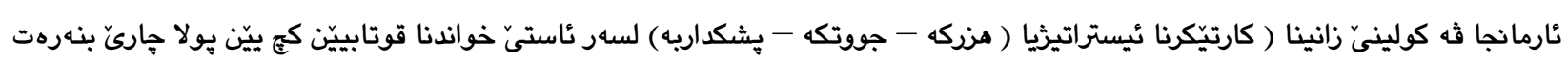

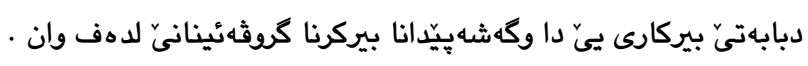

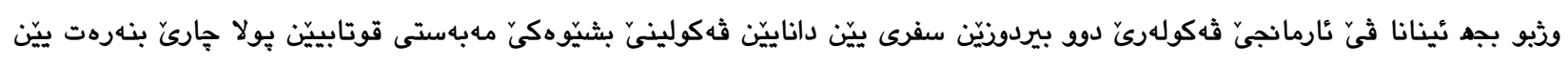

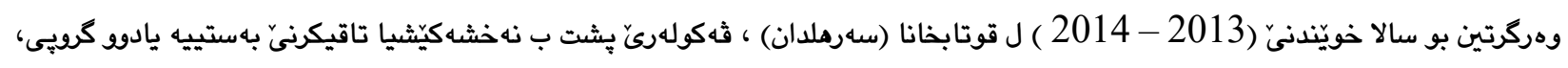

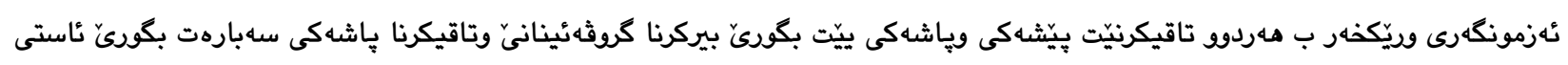

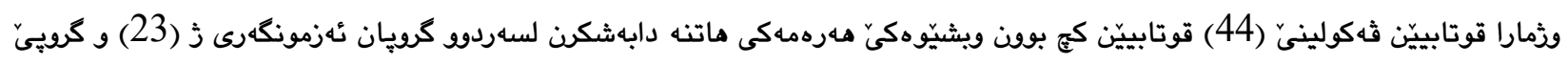

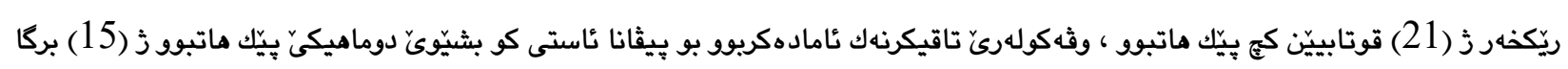

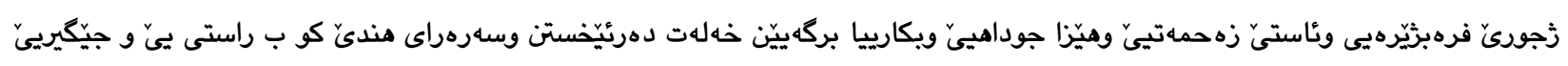

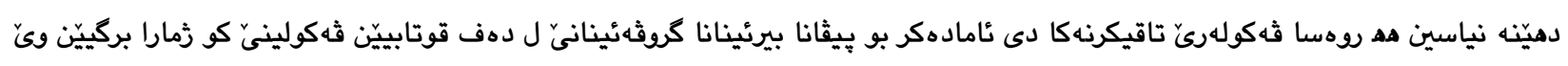

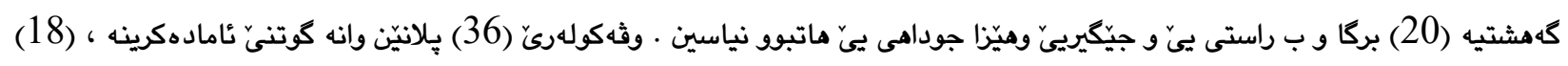

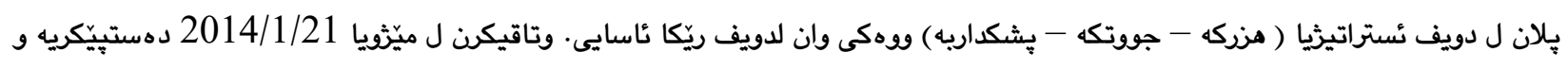

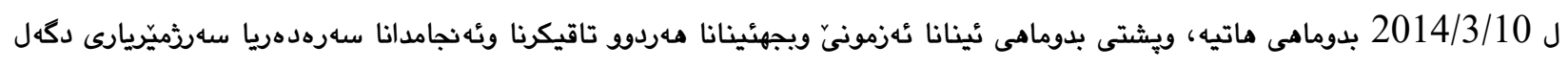
داتايا و بكارئينانا تاقيكرنا تائى (T-Test) : 1

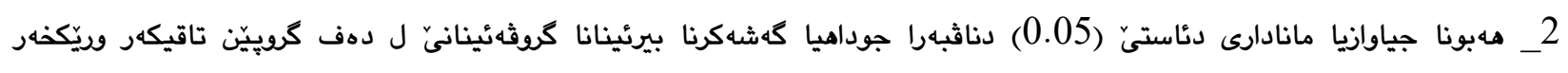

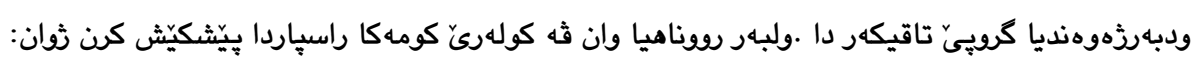

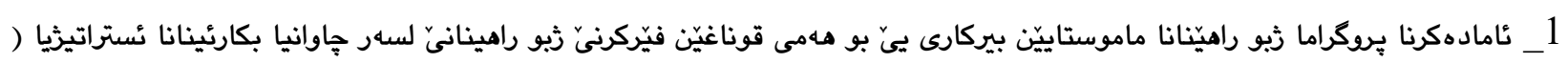

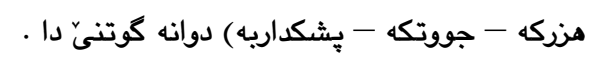

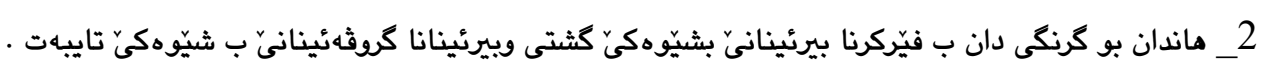

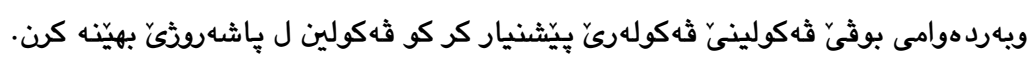

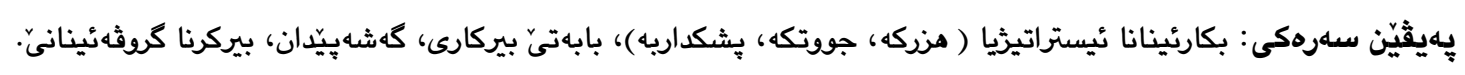




\title{
The Effectiveness of the recruitment strategy (think, pair, share) in the achievement of the fourth Basic class female students in mathematics, and its development of denotative thinking to them
}

\begin{abstract}
:
The research aims to identify the Effectiveness of the recruitment strategy (think - pair - share) in the achievement of the fourth Basic class female students in mathematics, and its development of denotative thinking to them. To achieve such a goal, the researcher put two null hypotheses. The research involved the fourth Basic class female students during the study year (2013-2014) in the intentionally selected (Sarhildan) school.

The researched adopted the experimental design of case-control study, with both pre-and posttesting for environmental awareness variable. However, the study only adopted the pre-testing for the achievement. The research sample included (44) Students randomly distributed in to two groups: an experimental group of (23) students, and a control group consisted of (21) students. The researcher prepared a test for measuring achievement composed of (15) multiple-choice question items characterized by validity and reliability, in order to obtain the item difficulty and discrimination indices and to evaluate the effectiveness of the wrong alternatives. Likewise, the researcher prepared a test for measuring denotative thinking comprised of (20) items characterized by validity, reliability, and differentiation. The research started on (21 Jan. 2014) and ended by (10 mar. 2014), during which the researcher gave lessons to both study groups. By completion of the research, application of research tools, data collection and statistical analysis by ( $\mathrm{t}$ - test), the following results were obtained:

1. There is a statistically significant difference at the level of (0.05) between the mean of the marks of the Experimental Group and Control Group and in favor of the Experimental Group.

2. There is a statistically significant difference at the level of $(0.05)$ between the mean of the difference in denotative thinking of the Experimental Group and Control Group and in favor of the Experimental Group.

In the light of the results, the researcher recommends the following:

1. Prepare training program for the teachers of mathematics in all level of education to train them how to use the strategy (think, pair, share) in studying.

2. Stimulate interest in teaching thinking in general and denotative thinking in particular.

To complement this study suggested that the researcher conducting research for the future.

Keywords: recruitment strategy (think, pair, share), mathematics, development, of denotative thinking.
\end{abstract}

